\title{
Increased platelet volume in a general population with prehypertension: a cross-sectional study of 80545 participants from China
}

\begin{abstract}
Xia Cao ${ }^{1,2}$, Xiumei Xie ${ }^{1}$, Jiansong Zhou ${ }^{3}$, Pingting Yang ${ }^{2}$, Yaqin Wang ${ }^{2}$ and Zhiheng Chen ${ }^{2}$
Mean platelet volume (MPV), an indicator of platelet activation, has been shown to be elevated in patients with hypertension. However, data available on the association between MPV level and prehypertension are limited. Prehypertension is also associated with an increase in cardiovascular morbidity and mortality. A cross-sectional study was performed among 80545 standardized medical checkup participants $\geqslant 18$ years in age without hypertension or diabetes in China between April 2009 and May 2010. Blood pressure was categorized as prehypertensive (systolic blood pressure, $120-140 \mathrm{~mm} \mathrm{Hg}$ and/or diastolic blood pressure, 80 to $90 \mathrm{~mm} \mathrm{Hg}, n=36586$ ) and normotensive (systolic blood pressure, $<120 \mathrm{~mm} \mathrm{Hg}$ and diastolic blood pressure, $<80 \mathrm{~mm} \mathrm{Hg}, n=43959$ ). Mean systolic blood pressure and the prevalence of prehypertension increased significantly with increasing MPV. After adjusting for demographics, body mass index, smoking and serum cholesterol, the odds ratio for prehypertension, when comparing the highest category of MPV ( $>12.0 \mathrm{fl})$ with the lowest category $(<10.1 \mathrm{fl})$, was $1.08(95 \%$ confidence interval, 1.02-1.13; $P$ for trend $=0.014$ ). This association persisted in separate analysis among men but not among women. In nonparametric models, the positive association between MPV and prehypertension appeared to be present across the full range of MPV, without any threshold effect. Increased MPV is associated with prehypertension in a large sample of Chinese adults that are free of cardiovascular disease and hypertension.
\end{abstract}

Hypertension Research (2012) 35, 903-908; doi:10.1038/hr.2012.62; published online 10 May 2012

Keywords: cardiovascular disease; mean platelet volume; prehypertension

\section{INTRODUCTION}

Platelets secrete and express a large number of substances that are crucial mediators of coagulation, inflammation, thrombosis and atherosclerosis. ${ }^{1}$ Platelets have a central role in the pathophysiology of cardiovascular diseases. ${ }^{2}$ It has been well demonstrated that patients with hypertension have evidence of platelet activation. ${ }^{3}$

Within an individual, platelets are heterogeneous in size and density. Mean platelet volume (MPV), an indicator of platelet activation, ${ }^{4}$ is one of the platelet function indices that reflects the rate of platelet production and stimulation. ${ }^{5}$ It has been shown that MPV is helpful in the differentiation of idiopathic thrombocytopenic purpura from other thrombocytopenias. ${ }^{6} \mathrm{MPV}$ is an important biological variable that is drawing increased interest as an independent risk factor for myocardial infarction. ${ }^{7}$ The literature on the association between MPV and stroke is inconsistent ${ }^{8,9}$ and may also relate to the use of different methods to assess MPV and the variable time points used for MPV measurement after stroke onset. ${ }^{10}$ Moreover, emerging evidence has shown that known cardiovascular risk factors, such as smoking, ${ }^{11}$ diabetes mellitus, ${ }^{12}$ obesity $^{13}$ and hypertension, ${ }^{14,15}$ are associated with MPV.
Prehypertension, as defined by the Seventh Joint National Committee, ${ }^{16}$ includes those with systolic blood pressure ranging $120-139 \mathrm{~mm} \mathrm{Hg}$ or diastolic blood pressure ranging $80-89 \mathrm{~mm} \mathrm{Hg}$, is identified as a predictor for developing hypertension ${ }^{17}$ and a stage where the primary prevention of hypertension is possible. ${ }^{18}$ Prehypertension is a risk factor for overt hypertension, and several small-scale studies have demonstrated the association of prehypertension with increased CVD morbidity. ${ }^{19}$ However, there are few data available on the association between MPV levels and prehypertension.

Our primary hypothesis is that MPV increases in prehypertensive individuals. Therefore, in this study, we examined whether an elevated MPV level was associated with blood pressure among non-diabetic and non-hypertensive subjects without a history of cardiovascular disease who attended a standardized medical checkup in 2009-2010, after adjusting for several important confounders. We also employed nonparametric analytical tools to graphically examine the doseresponse nature of the association between MPV levels and prehypertension. These findings might help identify prehypertensive

${ }^{1}$ Department of Cardiovascular Medicine, Xiangya Hospital, Central South University, Changsha, China; ${ }^{2}$ Department of Health Management Center, The Third Xiangya Hospital, Central South University, Changsha, China and ${ }^{3}$ Department of Psychiatrics, The Second Xiangya Hospital, The Central South University, Changsha, China

Correspondence: Professor Z Chen, Department of Health Management Center, The Third Xiangya Hospital, Central South University, Tongzipo Road 138, Hunan Prov., Changsha 410013, China.

E-mail: chenzhiheng588@yahoo.cn

Received 13 January 2012; revised 26 February 2012; accepted 27 February 2012; published online 10 May 2012 
individuals who are at increased risk for cardiovascular events and who might benefit from long-term treatment with antiplatelet agents.

\section{METHODS}

\section{Participants}

We reviewed the medical records of 118842 participants ( $\geqslant 18$ years, 66551 men and 52291 women) who voluntarily underwent medical examinations a the Health Management Center of the Third Xiangya Hospital in Hunan Province, China. The standardized medical checkup services included the administration of a medical questionnaire, physical examination and laboratory tests for a variety of adult diseases, such as hypertension, diabetes, hypercholesterolemia, liver disease, kidney disease and malignancy. The questionnaire and examinations were conducted by medical staff according to a standard protocol. Demographic, anthropometric and laboratory data were gathered for each subject within the same day. This study followed the recommendations of the Declaration of Helsinki. All the participants provided informed consent before entering the study, and approval was obtained from the Human Subjects Committee at the Third Xiangya Hospital, Central South University.

Data on systolic and diastolic blood pressure were available for 116465 participants (98\%). Ultimately, 21587 participants with prevalent hypertension, 5816 participants with diabetes (subjects with fasting blood glucose $>7.1 \mathrm{mmoll}^{-1}$, self-reported diabetes and/or treatment with insulin or oral antidiabetic medication were considered diabetics), 1458 participants with missing covariable data and subjects meeting any of the following criteria were excluded $(n=7059)$ to exclude the possibility of an inflammatory disorder, bone marrow suppressive disorder, renal and hepatic dysfunction, lipidlowering therapy or treatment with platelet function-modifying medications. The following subjects were also excluded from the study: those with a history of cardiovascular disease, stroke, malignancy and chronic liver disease; those with white blood cell counts of $<3.0$ or $>10.0 \times 10^{9}$ cells $^{-1}$; those with

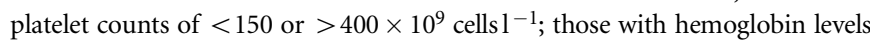
of $<12.0 \mathrm{~g} \mathrm{dl}^{-1}$ for females or $13.0 \mathrm{~g} \mathrm{dl}^{-1}$ for males; and those currently taking antiplatelet medication. After these exclusions, 80545 participants (47 710 men and 32835 women, aged 18-79 years) were included in the final analysis.

\section{Measurement of blood pressure}

Seated blood pressures were measured by skilled, trained physicians after subjects had rested for 15 min using a mercury sphygmomanometer according to the American Heart Association's recommendations. ${ }^{20}$ The average of three readings was recorded. The participants were considered hypertensive if they reported current blood pressure-reducing medication use and/or had systolic blood pressures $\geqslant 140 \mathrm{~mm} \mathrm{Hg}$ and/or diastolic blood pressures $\geqslant 90 \mathrm{~mm} \mathrm{Hg}^{16}$ Prehypertension was defined as systolic blood pressure measurements between 120 and $139 \mathrm{mmHg}$ and/or diastolic blood pressures between 80 and $89 \mathrm{~mm} \mathrm{Hg} .{ }^{16}$ Control subjects who had systolic blood pressure $<120 \mathrm{~mm} \mathrm{Hg}$ and diastolic blood pressure $<80 \mathrm{~mm} \mathrm{Hg}$ were diagnosed as normotensive controls.

\section{Measurement of other variables \\ The assessment of medical history, smoking status and medication was based on the standardized questionnaire in the medical record. Body mass index (BMI) was computed as weight in kilograms divided by the square of height in meters. Blood samples were drawn from the antecubital vein by careful venipuncture using a $21-\mathrm{G}$ sterile syringe without stasis at 0800-1000 hours after a fasting period of $12 \mathrm{~h}$. Lipid profiles were determined using the standard methods. MPV was measured in a blood sample collected in dipotassium EDTA tubes. An automatic blood counter (Sysmex XT 2000i analyzer, Sysmex Corporation, Kobe, Japan) was used for whole-blood counts. MPV was measured within $90 \mathrm{~min}$ after sampling to prevent EDTA-induced platelet swelling. The expected values for MPV in our laboratory ranged from 7.6 to $13.2 \mathrm{fl}$.}

\section{Statistical analysis}

Mean values and proportions were compared using analysis of variance and $\chi^{2}$ tests, respectively. We examined MPV levels as quintiles: $<10.1,10.1-10.7$,
10.7-11.3, 11.3-12.0 and > 12.0 fl. The relationship between MPV and blood pressure values was analyzed using multiple linear regression. Because of the skewed distribution of platelet parameters and to prevent the undue influence of observations with extreme values, these variables were log-transformed (natural $\log (\mathrm{x})$ ). The odds ratio (95\% confidence interval) of prehypertension was calculated for each MPV level, with the lowest quartile as the reference, using multivariable logistic regression models. We used age (years) and sexadjusted multivariable models that were additionally adjusted for smoking (never, former and current), alcohol intake (g per day), BMI $\left(\mathrm{kg} \mathrm{m}^{-2}\right)$, and serum cholesterol $\left(\mathrm{mmoll}^{-1}\right)$. Trends in the odds ratio of prehypertension across increasing MPV categories were determined, modeling MPV categories as an ordinal variable. To examine the consistency of the observed association between MPV levels and prehypertension, we performed subgroup analyses by gender, age ( $<50$ and $\geqslant 50$ years), current smoking (absent and present) and BMI $\left(<24\right.$ and $\left.\geqslant 24 \mathrm{~kg} \mathrm{~m}^{-2}\right)$. All the analyses were conducted using SAS statistical software (SAS Institute, Cary, NC, USA). All the statistical tests were two-sided and significance was determined at a $P$-value $<0.05$.

\section{RESULTS}

Among the 80545 adults without hypertension, diabetes and cardiovascular disease included in the current analysis, mean age was 40.11 years (range from 18 to 79 years), 32835 (40.77\%) were women and $36586(45.42 \%)$ individuals had prehypertension. Descriptive characteristics of the study population are presented in Table 1 and Table 2, for both the overall population and by MPV categories. Compared with those with lower MPV values, participants with higher levels of MPV ( $>11.3 \mathrm{fl})$ included a larger proportion of women, persons aged $\geqslant 50$ years, former smokers, those with education at the high school level or below, those with a higher waist circumference and those who were obese (Table 1). As expected, MPV was strongly associated with platelet count as well as platelet distribution width. Interestingly, increasing quintiles of MPV were also associated with slightly lower levels of total cholesterol and lowdensity lipoprotein cholesterol and increasing levels of high-density lipoprotein cholesterol. Systolic blood pressure and the prevalence of prehypertension increased with increasing MPV categories (Table 2).

Table 3 shows the standardized regression coefficients obtained from the multiple linear regression models for systolic blood pressure. Excluding female participants, MPV was linearly associated with systolic blood pressure after the adjustment for demographics and BMI.

Table 4 presents the odds ratios of prehypertension by increasing MPV quintiles. Increasing MPV quintiles were positively associated with prehypertension; models evaluating the trend in this association were also statistically significant. When MPV was analyzed as a continuous variable, the positive association with prehypertension persisted. In Table 5, we present the gender-specific analysis for the association between increasing MPV levels and prehypertension. A clear positive association between MPV and prehypertension was present among men, but among women, the results were indicative of a negative association.

In Table 6, we examined the odds ratio of prehypertension associated with increasing levels of log-transformed MPV within subgroups for education, age, current smoking and BMI. The associations between MPV and hypertension were present in all subgroups. The associations between MPV and prehypertension among women were markedly weakened in the fully adjusted model (including BMI, age and serum cholesterol). Similarly, the association between MPV and prehypertension seemed stronger among those who were younger than 50 years. The opposite was observed in both relative weight and smoking-status categories in this population but seemed to be stronger in the present smoking and high-body-weight groups. 
Table 1 Characteristics of the study population by categories of mean platelet volume ${ }^{a}$

\begin{tabular}{|c|c|c|c|c|c|c|c|}
\hline \multirow[b]{2}{*}{ Characteristics } & \multirow[b]{2}{*}{$\begin{array}{c}\text { Overall } \\
(\mathrm{n}=80545)\end{array}$} & \multicolumn{5}{|c|}{ Mean platelet volume categories } & \multirow[b]{2}{*}{ P-value } \\
\hline & & $\begin{array}{c}<10.1 \mathrm{fl} \\
(\mathrm{n}=16931)\end{array}$ & $\begin{array}{l}10.1-10.7 f 1 \\
(\mathrm{n}=17970)\end{array}$ & $\begin{array}{l}10.7-11.3 \mathrm{fl} \\
(\mathrm{n}=13763)\end{array}$ & $\begin{array}{l}11.3-12.0 f l \\
(\mathrm{n}=16115)\end{array}$ & $\begin{array}{c}>12.0 f l \\
(\mathrm{n}=15766)\end{array}$ & \\
\hline Age $\geqslant 50$ years, $\%$ & 18.8 & 17.6 & 18.1 & 18.0 & 19.2 & 20.9 & $<0.001$ \\
\hline Men, \% & 59.2 & 61.8 & 60.0 & 59.9 & 58.8 & 55.5 & $<0.001$ \\
\hline \multicolumn{8}{|c|}{ Education categories, \% } \\
\hline High school & 24.4 & 22.1 & 23.5 & 24.6 & 25.7 & 26.2 & \\
\hline Above high school & 42.5 & 46.7 & 44.3 & 40.3 & 39.7 & 40.6 & \\
\hline \multicolumn{8}{|l|}{ Smoking, \% } \\
\hline Never & 44.0 & 48.3 & 44.0 & 42.8 & 43.7 & 40.6 & $<0.001$ \\
\hline \multicolumn{8}{|l|}{ Body weight, \% } \\
\hline Normal & 58.3 & 58.9 & 58.3 & 58.2 & 57.6 & 58.5 & 0.20 \\
\hline Overweight & 33.3 & 33.3 & 33.2 & 33.1 & 33.9 & 33.0 & 0.47 \\
\hline Obese & 8.4 & 7.8 & 8.5 & 8.7 & 8.5 & 8.5 & 0.04 \\
\hline $\mathrm{BMI}, \mathrm{kg} \mathrm{m}^{-2}$, mean & 23.34 & 23.30 & 23.33 & 23.36 & 23.38 & 23.33 & 0.43 \\
\hline WC, cm, mean & 79.64 & 79.72 & 79.73 & 79.65 & 79.72 & 79.38 & $<0.01$ \\
\hline
\end{tabular}

Abbreviations: BMI, body mass index; WC, waist circumference.

ancludes all participants, unadjusted.

bNormal weight is defined as having a BMI between 18 and $23.9 \mathrm{~kg} \mathrm{~m}^{-2}$; overweight, between 24 and $27.9 \mathrm{~kg} \mathrm{~m}^{-2}$; obese,BMI $>28 \mathrm{~kg} \mathrm{~m}^{-2}$.

Table 2 Prevalence of prehypertension, mean levels of platelet parameters and mean blood pressures, by categories of mean platelet volume, adjusted for age and sex

\begin{tabular}{|c|c|c|c|c|c|c|c|}
\hline \multirow[b]{2}{*}{ Variables } & \multirow[b]{2}{*}{$\begin{array}{c}\text { Overall } \\
(\mathrm{n}=80545)\end{array}$} & \multicolumn{5}{|c|}{ Mean platelet volume categories } & \multirow[b]{2}{*}{$\begin{array}{l}\text { P-value for } \\
\text { trend }\end{array}$} \\
\hline & & $\begin{array}{c}<10.1 \mathrm{fl} \\
(\mathrm{n}=16931)\end{array}$ & $\begin{array}{l}10.1-10.7 \mathrm{fl} \\
(\mathrm{n}=17970)\end{array}$ & $\begin{array}{l}10.7-11.3 \mathrm{fl} \\
(\mathrm{n}=13763)\end{array}$ & $\begin{array}{l}11.3-12.0 f l \\
(\mathrm{n}=16115)\end{array}$ & $\begin{array}{c}>12.0 f l \\
(\mathrm{n}=15766)\end{array}$ & \\
\hline MPV, fl, mean & 10.96 & 9.50 & 10.41 & 11.00 & 11.58 & 12.47 & $<0.001$ \\
\hline $\begin{array}{l}\text { Platelet count, } 10^{9} \mathrm{I}^{-1} \text {, } \\
\text { mean }\end{array}$ & 202.83 & 232.24 & 214.03 & 202.53 & 190.48 & 171.36 & $<0.001$ \\
\hline PDW, fl, mean & 13.53 & 11.00 & 12.42 & 13.42 & 14.54 & 16.54 & $<0.001$ \\
\hline Prehypertension, \% & 45.4 & 44.8 & 45.4 & 45.0 & 45.9 & 46.0 & $<0.05$ \\
\hline $\mathrm{SBP}, \mathrm{mm} \mathrm{Hg}$, mean & 117.02 & 116.89 & 116.95 & 116.97 & 117.15 & 117.17 & $<0.05$ \\
\hline DBP, mm Hg, mean & 73.39 & 73.34 & 73.39 & 73.39 & 73.51 & 73.32 & 0.15 \\
\hline $\begin{array}{l}\text { Total cholesterol, mean, } \\
\mathrm{mmoll}^{-1}\end{array}$ & 4.74 & 4.79 & 4.75 & 4.74 & 4.72 & 4.70 & $<0.001$ \\
\hline $\begin{array}{l}\text { Triglycerides, mean, } \\
\mathrm{mmoll}^{-1}\end{array}$ & 1.46 & 1.47 & 1.45 & 1.47 & 1.46 & 1.46 & 0.14 \\
\hline $\begin{array}{l}\text { LDL cholesterol, mean, } \\
\mathrm{mmoll}^{-1}\end{array}$ & 2.70 & 2.76 & 2.72 & 2.70 & 2.68 & 2.64 & $<0.001$ \\
\hline $\begin{array}{l}\text { HDL cholesterol, } \\
\text { mean,mmol I-1 }\end{array}$ & 1.37 & 1.36 & 1.37 & 1.37 & 1.37 & 1.39 & $<0.001$ \\
\hline
\end{tabular}

Abbreviations: DBP, diastolic blood pressure; HDL, high-density lipoprotein; LDL, low-density lipoprotein; MPV, mean platelet volume; PDW, platelet distribution width; SBP, systolic blood pressure.

\section{DISCUSSION}

This large cross-sectional study in healthy Chinese adults shows that MPV is associated with prehypertension. After controlling for the main potential confounders (age, sex and BMI), as well as for other potentially relevant variables (smoking and serum cholesterol), high levels of MPV were associated with greater odds of prehypertension in a dose-response fashion (Table 4). The large sample size allowed us to conduct subsequent analysis employing nonparametric models (Table 6). The observed positive association between MPV and prehypertension was present continuously across the full range of 
MPV. Another interesting finding was the negative correlation between MPV and plasma lipid levels, which is considered a major cardiovascular risk factor. Although several studies have previously shown the association between MPV and hypertension, ${ }^{14,15,21,22}$ its relationship in subjects without hypertension is unknown. The latest studies have shown that prehypertension causes platelet activation, as demonstrated by increased MPV. ${ }^{23,24}$ To our knowledge, the present study is by far the largest study of the general population to examine the association of MPV with prehypertension.

MPV is the most commonly used measure of platelet size and is a marker of platelet reactivity. Large platelets aggregate in vitro more rapidly to agonists, such as ADP, collagen and adrenaline, than small platelets, release more thromboxane $\mathrm{A}_{2}$, serotonin and ATP, contain

Table 3 Linear regression analyses of systolic blood pressure on mean platelet volume $(n=80545)$

\begin{tabular}{|c|c|c|c|c|}
\hline \multirow[b]{2}{*}{ Variables } & \multicolumn{2}{|c|}{$\begin{array}{l}\text { Systolic blood } \\
\text { pressure, } m m \mathrm{Hg}, \\
\text { men }(\mathrm{n}=47710)\end{array}$} & \multicolumn{2}{|c|}{ 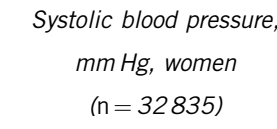 } \\
\hline & $\beta$ (s.e.) & $\mathrm{P}$-value & $\beta$ (s.e.) & P-value \\
\hline \multicolumn{5}{|c|}{ Mean platelet volume (log-transformed) } \\
\hline Age adjusted & $5.40(1.07)$ & $<0.001$ & $-0.21(1.32)$ & 0.88 \\
\hline Age and BMI-adjusted & $3.78(1.04)$ & $<0.001$ & $0.42(1.29)$ & 0.74 \\
\hline
\end{tabular}

Abbreviation: BMI, body mass index. more dense granules and express an increased number of P-selectin and GP IIb/IIA receptors. ${ }^{25}$

Several lines of recent evidence suggest that an association between MPV and hypertension is plausible. Nadar et al. ${ }^{26}$ found that MPV was significantly higher in patients with hypertension than in normotensive control subjects; within the hypertensive group, those with evidence of target organ damage had significantly larger platelets with greater mass than those without target organ damage. Coban et al. ${ }^{15}$ reported that MPV was significantly higher in essential hypertensives and white-coat hypertensives than in normotensives, and MPV was also higher in essential hypertensives than in white-coat hypertensives. Ordu et al. ${ }^{14}$ also showed that MPV is higher in nondipping hypertensive patients than in dipping hypertensive patients.

It is well demonstrated that prehypertension is related to an increased risk of death from cardiovascular disease. ${ }^{27-29}$ Despite much evidence for platelet activation in hypertension, data on prehypertensive patients are limited. In agreement with previous findings, ${ }^{30,31}$ we observed a strong association of increased MPV with older age, increasing BMI and smoking; however, after adjusting for these factors, the association of MPV with risk of prehypertension persisted, indicating that MPV was associated with a risk of prehypertension independently of these risk factors. The pathophysiological mechanisms leading to increased cardiovascular risk in prehypertension are still not understood. ${ }^{28}$ In hypertensive patients, there is a compelling evidence on the role of platelet activation in hypertensive thrombotic complications including stroke $^{32}$ and myocardial infarction. ${ }^{7}$ Increased platelet activation might be related to increased vascular thrombotic risk in

Table 4 Association between mean platelet volume and prehypertension

\begin{tabular}{|c|c|c|c|c|}
\hline Mean platelet volume categories & $\begin{array}{l}\text { Number at risk } \\
(\mathrm{n}=80545)\end{array}$ & $\begin{array}{c}\text { Prehypertension } \\
\text { cases }(n=36586)\end{array}$ & $\begin{array}{c}\text { Age, sex-adjusted } \\
\text { OR (95\% Cl) }\end{array}$ & $\begin{array}{c}\text { Multivariable-adjusted } \\
\text { OR }(95 \% \mathrm{Cl})^{\mathrm{a}}\end{array}$ \\
\hline$<10.1 \mathrm{fl}$ & 16931 & 7585 & 1 (referent) & 1 (referent) \\
\hline $10.1-10.7 \mathrm{fl}$ & 17970 & 8151 & $1.04(0.99-1.09)$ & $1.03(0.99-1.08)$ \\
\hline $10.7-11.3 \mathrm{fl}$ & 13763 & 6191 & $1.02(0.98-1.07)$ & $1.01(0.96-1.06)$ \\
\hline $11.3-12.0 \mathrm{fl}$ & 16115 & 7404 & $1.07(1.02-1.11)$ & $1.05(1.00-1.10)$ \\
\hline$>12.0 \mathrm{fl}$ & 15766 & 7255 & $1.09(1.04-1.14)$ & $1.08(1.02-1.13)$ \\
\hline$P$-trend & & & 0.01 & 0.01 \\
\hline $\begin{array}{l}\text { Mean platelet volume } \\
\text { (log-transformed) }\end{array}$ & 80545 & 36586 & $1.86(1.41-2.80)$ & $1.85(1.31-2.63)$ \\
\hline
\end{tabular}

Abbreviations: $\mathrm{Cl}$, confidence interval; $\mathrm{OR}$, odds ratio.

${ }^{a}$ Adjusted for age (years), sex (men and women), smoking (never, former and current), body mass index ( $\mathrm{kg} \mathrm{m}^{-2}$ ), serum uric acid and serum cholesterol (mmol $\mathrm{I}^{-1}$ ),

Table 5 Association between increasing mean platelet volume levels and prehypertension by gender

\begin{tabular}{|c|c|c|c|c|}
\hline \multirow[b]{2}{*}{ Mean platelet volume quintiles } & \multicolumn{2}{|c|}{$\operatorname{Men}(n=47710)$} & \multicolumn{2}{|c|}{ Women $(\mathrm{n}=32835)$} \\
\hline & $\begin{array}{c}\text { Numbers of } \\
\text { prehypertension }\end{array}$ & $\begin{array}{c}\text { Multivariable-adjusted } \\
\text { OR }(95 \% \mathrm{Cl})\end{array}$ & $\begin{array}{c}\text { Numbers of } \\
\text { prehypertension }\end{array}$ & $\begin{array}{c}\text { Multivariable-adjusted } \\
\text { OR }(95 \% \mathrm{Cl})\end{array}$ \\
\hline Quintile $1(<10.1)$ & 5650 & 1 (referent) & 1935 & 1 (referent) \\
\hline Quintile 2 (10.1-10.7) & 5978 & $1.05(0.99-1.11)$ & 2173 & $0.99(0.92-1.07)$ \\
\hline Quintile 3 (10.7-11.3) & 4527 & $1.02(0.96-1.09)$ & 1663 & $0.97(0.90-1.06)$ \\
\hline Quintile 4 (11.3-12.0) & 5374 & $1.08(1.02-1.15)$ & 2029 & $0.97(0.90-1.06)$ \\
\hline Quintile 5 (>12.0) & 4963 & $1.08(1.01-1.14)$ & 2291 & $1.05(0.98-1.14)$ \\
\hline$P$-trend & & 0.04 & & 0.24 \\
\hline Mean platelet volume (log-transformed) & & $1.98(1.28-3.07)$ & & $1.36(0.76-2.46)$ \\
\hline
\end{tabular}

Abbreviations: $\mathrm{Cl}$, confidence interval; OR, odds ratio.

Adjusted for age (years), sex (men and women), smoking (never, former and current), body mass index $\left(\mathrm{kg} \mathrm{m}^{-2}\right)$ and serum cholesterol (mg dl ${ }^{-1}$ ). 
Table 6 Association between mean platelet volume level and prehypertension within selected subgroups

\begin{tabular}{|c|c|c|c|}
\hline $\begin{array}{l}\text { Stratified } \\
\text { subgroups }\end{array}$ & $\begin{array}{l}\text { Number of } \\
\text { individuals }\end{array}$ & $\begin{array}{c}\text { Number of } \\
\text { prehypertension }\end{array}$ & $\begin{array}{c}\text { Multivariable-adjusted OR } \\
\text { (95\% Cl) of prehypertension } \\
\text { associated with log-transformed } \\
\text { MPV, fl, within each subgroup }\end{array}$ \\
\hline \multicolumn{4}{|l|}{ Age, years } \\
\hline$<50$ years & 64441 & 34060 & $2.06(1.39-3.05)^{\mathrm{a}}$ \\
\hline$\geqslant 50$ years & 15104 & 2526 & $1.75(0.81-3.79)$ \\
\hline \multicolumn{4}{|l|}{ Current smoking } \\
\hline Absent & 66852 & 30424 & $1.03(1.01-1.05)^{\mathrm{a}}$ \\
\hline Present & 13693 & 6162 & $1.52(1.50-1.55)^{\mathrm{a}}$ \\
\hline \multicolumn{4}{|l|}{ Body mass index } \\
\hline$<24 \mathrm{~kg} \mathrm{~m}^{-2}$ & 47846 & 31695 & $1.55(1.22-1.96)^{\mathrm{a}}$ \\
\hline$\geqslant 24 \mathrm{~kg} \mathrm{~m}^{-2}$ & 32699 & 4891 & $2.36(1.49-3.74)^{\mathrm{a}}$ \\
\hline
\end{tabular}

Abbreviations: $\mathrm{Cl}$, confidence interval; OR, odds ratio.

Adjusted for age (years), sex (men and women), smoking (never, former and current), body mass index $\left(\mathrm{kg} \mathrm{m}^{-2}\right)$ and serum cholesterol $\left(\mathrm{mg} \mathrm{dl}^{-1}\right)$.

${ }^{a} P<0.05$.

prehypertension. However, in our study, increased MPV was negatively correlated with plasma total cholesterol, and low-density lipoprotein cholesterol was negatively correlated with minimal changes in absolute numbers. Additionally, adjustment for these factors did not change the risk estimates for the association between MPV and prehypertension. Altogether, these results suggest that the risk of prehypertension associated with MPV cannot be explained by atherosclerosis alone and that high MPV may be associated with the risk for prehypertension independently of lipid levels.

This study has several limitations that are worth mentioning. First, because of the observational and cross-sectional nature of the study, these results should be interpreted with caution. The hypothesis of a causal association between platelet activation and prehypertension is supported by the evidence from intervention trials, suggesting a significant increase in MPV in prehypertensive subjects; these trials also showed a decrease in MPV after lifestyle modification for 20 weeks in a small sample of patients. ${ }^{33}$ Further, prospective studies on the longitudinal association between MPV in relation to changes in blood pressure and prehypertension will help elucidate the true nature and magnitude of the association. Second, our study took place in a single center from a large urban teaching hospital, and the study population was a relatively homogeneous population in which a number of risk factors had been excluded. Therefore, the results of the current study may not be extrapolated to the entire prehypertensive cohort. Third, the exclusion of participants because of cardiovascular disease relied solely on the patients' history rather on than objective evidence. Another limitation was our use of EDTA as an anticoagulant; EDTA can cause time-dependent swelling in platelets. $^{34}$ Platelet counts and MPV were determined using an automatic blood counter within $1.5 \mathrm{~h}$ of blood sampling to prevent EDTA-induced platelet swelling.

\section{CONCLUSIONS}

In conclusion, our results suggest a positive association between higher MPV levels and prehypertension, as shown by the magnitude of this association. The results also suggest that the prehypertensive status was independent from traditional factors, such as smoking, BMI and age, a dose-response trend in nonparametric models and the consistency of this association in subgroup analyses by gender and several other factors. Although we are unable to determine whether higher MPV levels have a causative effect, these findings suggest that increased MPV levels in a prehypertensive group should be considered as a risk factor for cardiovascular disease.

\section{CONFLICT OF INTEREST}

The authors declare no conflict of interest.

\section{ACKNOWLEDGEMENTS}

This work was supported by the National Natural Science Foundation of China (NSFC, 30800368). We thank Chang Liu, MD, for his help in programming and statistical analyses, as well as all the participants for their contribution. Xia Cao (the first author) drafted the manuscript and performed the statistical analysis. The guarantor, Zhiheng Chen, accepts full responsibility for the work, had access to the data and controlled the decision to publish. Xiumei Xie helped to draft the manuscript. Jiansong Zhou, Pingting Yang and Yaqin Wang provided statistical expertise and critical corrections to the manuscript. All the authors read and approved the final manuscript.

1 Park $\mathrm{Y}$, Schoene N, Harris W. Mean platelet volume as an indicator of platelet activation: methodological issues. Platelets 2002; 13: 301-306.

2 Gawaz M, Langer H, May AE. Platelets in inflammation and atherogenesis. J Clin Invest 2005; 115: 3378-3384.

3 Nadar SK, Caine GJ, Blann AD, Lip GY. Platelet adhesion in hypertension: application of a novel assay of platelet adhesion. Ann Med 2005; 37: 55-60.

4 Jagroop IA, Tsiara S, Mikhailidis DP. Mean platelet volume as an indicator of platelet activation: methodological issues. Platelets 2003; 14: 335-336.

5 Ozhan H, Aydin M, Yazici M, Yazgan O, Basar C, Gungor A, Onder E. Mean platelet volume in patients with non-alcoholic fatty liver disease. Platelets 2010; 21: 29-32.

6 Ntaios G, Papadopoulos A, Chatzinikolaou A, Saouli Z, Karalazou P, Kaiafa G, Girtovitis F, Kontoninas Z, Savopoulos C, Hatzitolios A, Alexiou-Daniel S. Increased values of mean platelet volume and platelet size deviation width may provide a safe positive diagnosis of idiopathic thrombocytopenic purpura. Acta haematologica 2008; 119: 173-177.

7 Varol E, Icli A, Ozaydin M, Erdogan D, Arslan A. Mean platelet volume is elevated in patients with myocardial infarction with normal coronary arteries, as in patients with myocardial infarction with obstructive coronary artery disease. Scand J Clin Lab Invest 2009; 69: 570-574.

8 Bath P, Algert C, Chapman N, Neal B. Association of mean platelet volume with risk of stroke among 3134 individuals with history of cerebrovascular disease. Stroke 2004; 35: 622-626.

9 Ntaios G, Gurer O, Faouzi M, Aubert C, Michel P. Hypertension is an independent predictor of mean platelet volume in patients with acute ischaemic stroke. Intern Med J 2011; 41: 691-695.

10 Ntaios G, Gurer O, Faouzi M, Aubert C, Michel P. Mean platelet volume in the early phase of acute ischemic stroke is not associated with severity or functional outcome. Cerebrovasc Dis 2010; 29: 484-489.

11 Kario K, Matsuo T, Nakao K. Cigarette smoking increases the mean platelet volume in elderly patients with risk factors for atherosclerosis. Clin Lab Haematol 1992; 14: 281-287.

12 Papanas N, Symeonidis G, Maltezos E, Mavridis G, Karavageli E, Vosnakidis T, Lakasas G. Mean platelet volume in patients with type 2 diabetes mellitus. Platelets 2004; 15: 475-478.

13 Coban E, Adanir H, Bilgin D. The association of mean platelet volume levels with hypertensive retinopathy. Platelets 2008; 19: 115-118.

14 Ordu S, Ozhan H, Caglar O, Alemdar R, Basar C, Yazici M, Erden I. Mean platelet volume in patients with dipper and non-dipper hypertension. Blood Press 2010; 19: 26-30.

15 Coban E, Yazicioglu G, Berkant Avci A, Akcit F. The mean platelet volume in patients with essential and white coat hypertension. Platelets 2005; 16: 435-438.

16 Chobanian AV, Bakris GL, Black HR, Cushman WC, Green LA, Izzo Jr JL, Jones DW, Materson BJ, Oparil S, Wright Jr JT, Roccella EJ. Seventh report of the Joint National Committee on prevention, detection, evaluation, and Treatment of high blood pressure. Hypertension 2003; 42: 1206-1252.

17 Vasan RS, Larson MG, Leip EP, Kannel WB, Levy D. Assessment of frequency of progression to hypertension in non-hypertensive participants in the Framingham Heart Study: a cohort study. Lancet 2001; 358: 1682-1686.

18 Whelton PK, He J, Appel LJ, Cutler JA, Havas S, Kotchen TA, Roccella EJ, Stout R, Vallbona C, Winston MC, Karimbakas J. Primary prevention of hypertension: clinical and public health advisory from The National High Blood Pressure Education Program. JAMA 2002; 288: 1882-1888. 
19 Kiely AE, Kwatra SG, Kwatra MM. Treating prehypertension: medically sound and economically viable. Blood Press 2009; 18: 300-303.

20 Perloff D, Grim C, Flack J, Frohlich ED, Hill M, McDonald M, Morgenstern BZ. Human blood pressure determination by sphygmomanometry. Circulation 1993; 88: 2460-2470.

21 Piazze J, Gioia S, Maranghi L, Anceschi M. Mean platelet and red blood cell volume measurements to estimate the severity of hypertension in pregnancy. $J$ Perinat Med 2006; 34: 246-247.

22 Wasilewska A, Tenderenda E, Taranta-Janusz K, Zoch-Zwierz W. High-sensitivity C-reactive protein and mean platelet volume in paediatric hypertension. Pediatr Nephrol 2010; 25: 1519-1527.

23 Yuksel C, Celik T, Demirkol S, Celik M, Bugan B, Iyisoy A, Yaman H. Increased platelet activation in young patients with prehypertension. Clin Exp Hypertens 2011; 33 381-387.

24 Varol E, Akcay S, Icli A, Yucel H, Ozkan E, Erdogan D, Ozaydin M. Mean platelet volume in patients with prehypertension and hypertension. Clinical hemorheology and microcirculation 2010; 45: 67-72.

25 Ntaios G, Gurer O, Faouzi M, Aubert C, Michel P. Mean platelet volume in the early phase of acute ischemic stroke is not associated with severity or functional outcome. Cerebrovasc Dis 2010; 29: 484-489.

26 Nadar SK, Blann AD, Kamath S, Beevers DG, Lip GY. Platelet indexes in relation to target organ damage in high-risk hypertensive patients: a substudy of the Anglo-Scandinavian Cardiac Outcomes Trial (ASCOT). J Am Coll Cardiol 2004; 44 415-422.
27 Zhang M, Batu B, Tong W, Li H, Lin Z, Li Y, Zhang X, Zhang Y. Prehypertension and cardiovascular risk factor clustering among Mongolian population in rural and animal husbandry area, Inner Mongolia, China. Circ J 2009; 73: 1437-1441.

28 Nery AB, Mesquita ET, Lugon JR, Kang HC, de Miranda VA, de Souza BG, Andrade JA Rosa ML. Prehypertension and cardiovascular risk factors in adults enrolled in a primary care programme. Eur J Cardiovasc Prev Rehabil 2011; 18: 233-239.

29 Gu D, Chen J, Wu X, Duan X, Jones DW, Huang JF, Chen CS, Chen JC, Kelly TN, Whelton PK, He J. Prehypertension and risk of cardiovascular disease in Chinese adults. J Hypertens 2009; 27: 721-729.

30 Boos CJ, Lip GY. Assessment of mean platelet volume in coronary artery disease - what does it mean? Thromb Res 2007; 120: 11-13.

31 Muscari A, De Pascalis S, Cenni A, Ludovico C, Castaldini N, Antonelli S, Bianchi G, Magalotti D, Zoli M. Determinants of mean platelet volume (MPV) in an elderly population: relevance of body fat, blood glucose and ischaemic electrocardiographic changes. Thromb Haemost 2008; 99: 1079-1084.

32 Pikija S, Cvetko D, Hajduk M, Trkulja V. Higher mean platelet volume determined shortly after the symptom onset in acute ischemic stroke patients is associated with a larger infarct volume on CT brain scans and with worse clinical outcome. Clinical Neurol Neurosurg 2009; 111: 568-573.

33 Yazici M, Kaya A, Kaya Y, Albayrak S, Cinemre H, Ozhan H. Lifestyle modification decreases the mean platelet volume in prehypertensive patients. Platelets 2009; 20: 58-63.

34 Boos CJ, Balakrishnan B, Lip GY. The effects of coronary artery disease severity on time-dependent changes in platelet activation indices in stored whole blood. J Thromb Thrombolysis 2008; 25: 135-140. 